\title{
Decisión, decisiones y consecuencias de la primera codificación canónica: el caso de la idoneidad para recibir las órdenes sagradas
}

\author{
Decision, Decisions and Impact of the First Codification \\ of Canon Law: Case Study of the Suitability of Candidates \\ for Sacred Orders
}

Nicolás ÁLVAREZ DE LAS ASTURIAS

Catedrático de Historia del Derecho Canónico

Universidad Eclesiástica San Dámaso. Facultad de Derecho Canónico. Madrid orcid 0000-0003-3630-3516

nalvarez@sandamaso.es

Resumen: El centenario de la primera codificación canónica, en la medida en que ha sido precedida por rigurosos estudios históricos, es una ocasión propicia para reflexionar sobre las consecuencias que ha tenido para el derecho eclesial (y la misma vida de la Iglesia), tanto la decisión misma de adoptar la técnica codificatoria como las decisiones tomadas para configurar algunas instituciones canónicas. En este artículo se valorarán algunas de esas decisiones, ya estudiadas, y se presentará el modo en que se estableció la disciplina sobre la idoneidad para acceder al sacerdocio.

Palabras clave: Código de derecho canónico de 1917, Orden sagrado, Idoneidad.
Abstract: The centenary of the first codification of canon law has been preceded by rigorous historical studies, and serves as an occasion to reflect on the impact it has had on ecclesial law (and the life of the Church itself), both in terms of the decision to adopt codification as an instrument, and the decisions taken to structure some canonical institutions. Having previously been studied, a number of these decisions are assessed in this paper, before presenting the way in which the canonical discipline regarding the suitability of candidates for the priesthood was established.

Keywords: Code of Canon Law (1917), Holy Orders, Suitability. 


\section{INTRODUCCIÓN: UN CENTENARIO BIEN PREPARADO}

L a conmemoración del centenario de la primera codificación canónica ha encontrado a la comunidad científica bien preparada, dando ocasión para hacer fructificar aún más los fecundos trabajos de los últimos treinta años.

En efecto, hace ahora treinta años, Giorgio Feliciani presentaba un ambicioso proyecto de investigación, con la finalidad de estudiar el proceso de elaboración del Código pío-benedictino y poder así conocer la opciones tomadas ${ }^{1}$. De este modo, estaríamos en condiciones de valorar adecuadamente su lugar en la historia del derecho canónico y los cambios reales que introdujo en la vida jurídica de la Iglesia. Como se sabe, en relación con este proyecto del profesor Feliciani, pero no sólo, se han publicado en los últimos decenios numerosos estudios parciales que han permitido conocer el iter de elaboración de numerosas partes del Código².

Además, en 2008, Carlo Fantappiè publicó su monumental Chiesa romana e modernità giuridica, que constituye en muchos aspectos un acercamiento insuperable al código de $1917^{3}$. Así, gracias a la obra de Fantappiè contamos con los elementos necesarios para estudiar "históricamente" el primer código canónico, que queda convenientemente encuadrado en las dinámicas eclesiológicas y canónicas de la modernidad, quedando también puesta de manifiesto su influencia en la evolución posterior del derecho canónico. Como acertadamente señala Gherri, a la obra de Fantappiè difícilmente se le puede

${ }^{1}$ G. FELICIANI, Lineamenti di ricerca sulle origini della codificazione canonica, ahora en IDEM, Le pietre, il ponte e l'arco. Scritti scelti, Milano 2012, 3-17 (el original fue publicado en 1982).

2 Vid. M. Vismara Missiroli - L. Musselli, Il processo di codificazione del diritto penale canonico, Padova 1983; F. FALCHI, I chierici nel processo di formazione del codice pio-benedettino, Padova 1987; R. ASTORRI, Le leggi della Chiesa tra codificazione latina e diritti particolari, Padova 1992; E. DIENI, Tradizione juscorporalista e codificazione del matrimonio canonico, Milano 1999; J. LLOBELL - E. DE LEÓN - J. NAVARRETE, Il libro «De processibus» nella codificazione del 1917. Studi e documenti, vol. I, Milano 1999, 17-86; V. TURCHI, Le disposizioni preliminari sul matrimonio nel processo di codificazione piano-benedettino, Napoli 2001; G. MoRI, I religiosi nella codificazione canonica pio-benedettina. Sedimentazioni e nuovi assetti, Firenze 2004.

3 Vid. C. Fantappiè, Chiesa Romana e modernità giuridica, Milano 2008. Una presentación global de esta obra puede verse en P. GROSSI, Chiesa Romana e modernità giuridica (a proposito di un'opera recentissima di Carlo Fantappiè), en IdEM, Scritti canonistici, ed. de C. FantappIE, Milano 2013, 293 312. También, con una valoración crítica en N. ÁlVAREZ DE LAS AsTuRIAS, Il Codice di Diritto Canonico di 1917 quale oggetto storico, Ius Ecclesiae 23 (2011) 745-763. Cfr. también J. SEDANO, Iglesia y modernidad jurídica. Una contribución a la bistoria del pensamiento jurídico moderno en la monografía de Carlo Fantappiè, Ius Canonicum 52 (2011) 767-798. 
añadir algo; en todo caso, intentar reescribirla a partir de un punto de vista diverso ${ }^{4}$.

Conmemoración, pues, excelentemente preparada, pero... ¿qué nos condena quizás a repetir tan solo lo ya sabido? ¿Puede, pues, considerarse el código pío-benedictino algo ya completamente investigado, suficientemente conocido? La respuesta debe der ser negativa, al menos por tres razones.

La primera, porque que un argumento haya sido estudiado en profundidad, no quiere decir que los resultados de dicho estudio sean automáticamente patrimonio común, ni siquiera de la comunidad científica. Además, en el caso del derecho canónico, arrastramos desde hace tiempo una cuasi total separación entre los estudios históricos y los dedicados al derecho vigente, que llevan indefectiblemente al desconocimiento mutuo. En este sentido, las conmemoraciones de las distintas efemérides históricas, en la medida en que logran interesar a un público más amplio del habitual, desempeñan un papel no pequeño en la difusión operativa de conocimientos ya adquiridos.

La segunda, porque en la medida en que la historia se considera una ciencia del espíritu (o un arte), la cuestión de la interpretación resulta esencial $^{5}$. Y así el conocimiento, quizás exhaustivo, de los datos, no agota el conocimiento histórico, que requiere siempre interpretación. De hecho, la obra de Fantappiè -como no podía ser de otra manera- no ofrece sólo datos; ni siquiera principalmente datos. Lo que ofrece es un intento de reconstrucción (de interpretación en último término) de todo un proceso histórico y de sus consecuencias. Tanto sobre lo uno como sobre lo otro, cabe discusión crítica; cabe profundización; caben planteamientos complementarios, a la luz de datos no tenidos suficientemente en cuenta, o interpretados diversamente, o sencillamente ignorados. Es decir, cabe investigación histórica.

\footnotetext{
${ }^{4} \ll \ldots$ opera alla quale non è facile aggiungere nulla, tranne tentando di ri-efettuare praticamente da zero una ricerca della stessa portata ed estensione, ma da un differente punto di vista». P. GHERRI, Codificazione canonica tra tecnica e sistema, Eastern Canon Law 2 (2013) I, 19-130, aquí 19.

5 «Denominamos interpretación la comprensión técnica de manifestaciones de vida fijadas por escrito», W. DiLThey, El mundo bistórico, México 1944, 337. En general, sobre el conocimiento histórico, vid. E. DE La LAMA, Historia, en C. IzQuierdo (dir.), Diccionario de Teología, Pamplona 2006, 439-459.
} 
Por lo que a interpretación se refiere, la valoración del código pío-benedictino se mueve en torno a dos extremos: el de la interpretación oficial de sus creadores, que minimiza al máximo las posibles innovaciones, presentándolo como un nuevo modo de expresar un derecho ya existente y conocido; y la que emerge de los estudios de Fantappiè y de tantos otros, que ponen de manifiesto las enormes novedades (y en ciertos casos rupturas con el derecho anterior) que la codificación supuso.

Finalmente, la tercera tiene que ver con lo particular y lo presente. Con lo particular, porque los estudios hasta ahora señalados han delineado la arquitectura general del primer código canónico, sus grandes elecciones y su modo global de elaboración. Pero cualquiera que tenga un mínimo de experiencia académica sabe hasta qué punto el código de 1917 sigue siendo una cantera inmensa de tesis doctorales sobre argumentos concretos cuyo estudio todavía no se ha realizado. Con el presente, porque la historia es magistra vitae y en relación con las necesidades del presente es legítimo estudiarla. Y el presente eclesial viene ahora marcado también por la próxima asamblea ordinaria del Sínodo de los Obispos sobre los jóvenes, el discernimiento y la vocación ${ }^{6}$. En este sentido, estudiar cuanto el primer código canónico dice sobre la idoneidad para recibir las órdenes sagradas puede ayudar, si bien indirectamente, a reflexionar sobre la cuestión del discernimiento, propuesta por el Santo Padre Francisco.

Con todo lo dicho, creo estar en condiciones de justificar tanto el título como la estructura de este artículo. Por encuadrarse en un ámbito conmemorativo no podía no tratar las cuestiones principales referidas a la primera codificación canónica: la decisión de adoptar la técnica codificatoria, el modo de hacerlo y sus consecuencias. Por su índole científica, no debía contentarse con ofrecer un resumen más o menos certero de lo por otros realizado. De ahí, que busque ilustrarse la cuestión del modo concreto de codificar el derecho antiguo en lo referido a la idoneidad para recibir las órdenes sagradas. De este modo, espero, por una parte, mostrar en caso concreto cuanto de continuidad y cuanto de novedad se dio y, por otra, ilustrar mínimamente el interés que los estudios históricos pueden tener para el presente eclesial, rompiendo una lanza a favor del final del pernicioso distanciamiento en que solemos vivir canonistas e historiadores del derecho canónico.

${ }^{6}$ Vid. Ś́NODO DE LOS OBISPOS, Los jóvenes, la fe y el discernimiento vocacional: documento preparatorio para la XV Asamblea Ordinaria. 


\section{LA "DECISIÓN" DE CODIFICAR EL DERECHO CANÓNICO Y LA LABOR DE “TRADUCCIÓN"}

La necesidad de codificar el derecho canónico, puede decirse que fue un "clamor" durante la celebración del concilio Vaticano $\mathrm{I}^{7}$, fundamentalmente por razones de índole práctico: la pluralidad de fuentes, la contradicción entre ellas y su publicación en lugares diversos, hacía de la aplicación del derecho canónico (que para eso está), una labor prácticamente imposible.

Por otra parte, "codificar el derecho" había sido la tarea a la que se había dedicado con notable éxito y entusiasmo la ciencia jurídica continental, al menos desde los tiempos napoleónicos ${ }^{8}$. En términos más recientes podríamos decir que la codificación aparecía como un "signo de los tiempos", que la Iglesia debía reconocer y asumir en su caminar histórico.

El "clamor", sin embargo, debió esperar a ser escuchado a que accediera al pontificado Giuseppe Sarto, que tomaría el nombre de Pío X y que adoptaría como lema instaurare omnia in Christo. Su currículum de eclesiástico que había sido previamente párroco, explicaría su interés por un proyecto de índole tan práctica y tan necesario para hacer operativo el derecho de la Iglesia ${ }^{9}$.

La narración apenas esbozada, siendo toda ella verdadera es, a la vez, profundamente incompleta. Omite, en efecto, tanto las vacilaciones sobre el contenido y alcance que debería tener la reforma del derecho canónico, como -sobre todo- la posible existencia de otras causas complementarias a la evidente de carácter práctico.

En efecto, el "clamor" con ocasión del Vaticano I fue unánime en la necesidad de reforma del derecho canónico, no en la adopción de la técnica

\footnotetext{
${ }^{7}$ Vid. G. Feliciani, Il Concilio Vaticano I e la codificazione del diritto canonico, en Studi in onore di Ugo Gualazzini, vol. 2, Milano 1981, 35-80.

${ }^{8}$ Sobre las codificaciones civiles del siglo XIX, puede verse una presentación sintética en A. PADOA SCHIOPpA, Storia del diritto in Europa. Dal medioevo all'età contemporanea, Bologna 2007, 456-477. Los textos de la conocida polémica sobre la codificación en Alemania, pueden verse en J. STERN (ed.), Thibaut y Savigny. La Codificación: una controversia programática basada en sus obras 'Sobre la Necesidad de un Derecho Civil General para Alemania' y 'De la vocación de nuestra época para la legislación y la ciencia del Derecho' con adiciones y juicios de sus contemporáneos, Madrid 1970.

9 La importancia de Pío X en todo el proceso de codificación, ha sido puesto de manifiesto en numerosas publicaciones recientes. Baste de momento, citar la obra colectiva de A. CaTtaneo (cur.), L'eredità giuridica di San Pio X, Venezia 2006, y C. Minelli, Pio X e l'avvio del processo di codificazione, Stato, Chiese e pluralismo confessionale, Rivista telematica (www.statochiese.it) n. 33/2013. Cfr. también el reciente artículo de V. GómEZ-IGLESIAS C., Acerca de la trascendencia bistórica de la iniciativa de san Pio X de elaborar un código de derecho canónico, Ius Ecclesiae 29 (2017) 51-76.
} 
codicial ${ }^{10}$. De hecho, el inicio mismo de la reforma de Pío X dejaba abierta la cuestión y se barajaron distintas posibilidades, puesto que se trataba no de innovar, sino de hacer operativo un derecho ya consolidado. Entre los detractores de la asunción de la técnica codificadora estaban los que eran más conscientes de sus postulados ideológicos, incompatibles con la comprensión que el derecho canónico tenía de sí mismo. También probablemente los que veían en el futuro código una racionalización excesiva del derecho eclesial y, sobre todo, una ley cierta que impidiera los libres desarrollos administrativos y legislativos de los distintos dicasterios de la curia romana, fuentes productoras por antonomasia del derecho canónico de entonces.

Por otra parte, ¿el código buscaba tan solo resolver un problema práctico de índole intraeclesial (el de la aplicabilidad de su derecho)? Un canonista tan crítico y sensible como Francesco Ruffini, sospechaba ya en 1905 que se trataba de algo más y de naturaleza política. Se trataría también, según este canonista, de consolidar un modo de comprender las relaciones entre la Iglesia y el mundo; concretamente, las señaladas por el beato Pío IX en el Syllabus, sostenidas y fundadas ahora sobre los nuevos dogmas de la infalibilidad pontificia y de su primado de jurisdicción. El instaurare omnia in Christo de Pío X venía así interpretado como un intento de restauración de un programa parcialmente interrumpido durante el pontificado, más conciliador, de León XIII ${ }^{11}$.

¿Qué decir de todo esto? En primer lugar, que, al margen de las vacilaciones sobre la adopción o no de la técnica codificadora, de si debía ser exclusiva o sólo complementaria, la decisión final del papa Sarto fue la de codificar el derecho canónico, convirtiéndose el código en la única colección oficial desde su promulgación por Benedicto $\mathrm{XV}^{12}$.

Sin embargo, la decisión en favor de la codificación fue acompañada por todo un proceso de adaptación de esta técnica a las peculiaridades del derecho canónico. Concretamente, se modificó la autorreferencialidad propia de los códigos civiles, al prever la solución de lagunas legales y mantener (cfr. c. 20)

10 Vid. al respecto, G. FeLICIANI, Il concilio Vaticano I..., cit., 44-61, principalmente.

$11 \ll$ Ed ecco che ora -con l'evidente proposito di rinnovare anche in questo campo i tempi e le cose del pontificato di Pio IX-il pontefice Pio X ha ripresa arditamente l'opera lasciata in sospeso dal Concilio Vaticano». F. RUFFINI, La codificazione del diritto ecclesiastico, ahora en IDEM, Scritti giuridici minori, Milano 1936, I, 61-97, aquí 86; el original es de 1905.

12 La decisión de Pío X de realizar un código que sustituyese a todas las colecciones precedentes, en contra del parecer de muchos miembros de la curia y de diversos canonistas, resulta clara desde los inicios mismos de los trabajos. Cfr. al respecto C. FANTAPPIÈ, Chiesa romana..., cit., II, 675-676. 
las costumbres centenarias e inmemoriales (cfr. c. 5). Además, como ya se ha dicho, el código canónico no pretendía innovar respecto el derecho precedente, sino tan solo adaptarlo a las nuevas circunstancias y hacerlo más operativo a través de la técnica entonces en boga ${ }^{13}$. Se comprende así el valor que se concede a la tradición canónica como marco hermenéutico de la legislación codicial (cfr. c. 6). De este modo, una técnica surgida y utilizada en un contexto hostil a la Iglesia, pudo convertirse en un instrumento adecuado para la renovación del derecho canónico. Parafraseando a san Juan Pablo II, se puede decir que los redactores del código de 1917 debieron "traducir" a lenguaje eclesial una técnica civil con algunos presupuestos inicialmente incompatibles con la eclesiología y con el derecho canónico. El resultado de esta labor de traducción fue el primer código de la Iglesia católica.

En segundo lugar, que resulta indudable que pueden encontrarse otras motivaciones complementarias a la principal de índole práctica, que movieron a Pío X a poner en marcha y culminar la codificación del derecho de la Iglesia. En este sentido, Carlo Fantappiè ha puesto de manifiesto recientemente el valor "político" del código, como modo de apuntalar una de las grandes pretensiones de la eclesiología de sociedad perfecta y del ius pubblicum ecclesiasticum: a saber, el poder situarse en pie de igualdad ante los estados modernos, que exhibían su derecho flamantemente codificado ${ }^{14}$. Álvarez de las Asturias, por su parte, ha señalado hasta qué punto el código de 1917 se explica a la luz de los desarrollos eclesiológicos que, partiendo del concilio de Trento y configurándose a lo largo del siglo XIX en torno a la teología del primado, caracterizaban la eclesiología "oficial" o dominante entre los teólogos y canonistas de ámbito curial. A una eclesiología de ese tipo, la técnica codicial, con las adaptaciones mencionadas, se ajustaba como anillo al dedo ${ }^{15}$.

Cuestión diversa es si la decisión adoptada de codificar el derecho de la Iglesia, por los motivos apenas señalados y del modo concreto sucintamente descrito, tuvo o no más consecuencias de las inicialmente previstas. Es decir, si la

13 «Il modello codicistico viene dunque identificato da Pio X come lo strumento in quel momento più idoneo per stabilizzare il diritto canonico, per restituire certezza alle norme, per garantire l'applicazione della disciplina nei diversi ambiti in cui si esercita l'attività potestativa della Chiesa». Ibid., 677.

14 Vid. C. FANTAPPIÈ, El código de derecho canónico de 1917 y sus repercusiones para la vida de la Iglesia, Ius Communionis 5 (2017) 209-224.

15 Vid. N. ÁlvareZ de las Asturias, Derecho canónico y codificación: Alcance y límites de la asunción de una técnica, Ius Canonicum 51 (2011) 105-136, aquí 110-116. 
adopción de la técnica codificatoria supuso, de hecho, algún cambio en la concepción del derecho canónico y en su contenido; pero también, cuáles fueron las consecuencias reales de tener un derecho fácilmente aplicable. Para afrontar esta cuestión, es necesario detenerse en el proceso concreto de elaboración del código pío-benedictino para ilustrar cómo necesariamente tuvieron que tomarse "decisiones" que afectaron a la sustancia misma del derecho canónico.

\section{LAS "DECISIONES" EN EL PROCESO DE CODIFICACIÓN:}

EL CASO DE LA IDONEIDAD PARA EL ORDEN SAGRADO

En la constitución apostólica de promulgación del código de 1917, Benedicto XV señalaba que éste era el fruto del propósito principal de unum colligere toda la legislación precedente, ordenándola adecuadamente, removiendo las leyes ya abrogadas, acomodando otras a la nueva situación y estableciendo otras nuevas cuando se consideró necesario ${ }^{16}$.

Como no podía ser de otra manera, en este proceso de unificación y de relativa acomodación a los nuevos tiempos, fue necesario tomar una serie de "decisiones": en caso de disposiciones diversas, cuál preferir; en cuestiones doctrinalmente debatidas, por cuál decantarse. Así, de modo análogo a lo sucedido en los distintos momentos de unificación a lo largo de su historia, también la codificación supuso privilegiar ("canonizar" se podría decir literalmente) una entre varias opciones previamente legítimas. Sólo por esto, resulta ya claro que la promulgación del Código supuso un cambio respecto a la situación precedente más profunda de la que oficialmente se quería reconocer.

Pero supuso también optar entre las distintas corrientes teológicas y canónicas que explicaban de modo legítimamente diverso cuestiones abiertas, siendo la consecuencia lógica, un modo diverso de plantear la reforma legislativa de iure condendo en aspectos no marginales del ordenamiento canónico. Por citar sólo dos ejemplos, la opción por la explicación de la jurisdicción episcopal como inmediatamente recibida del papa, condicionó toda la redacción

${ }^{16}$ «Quibus de causis, idem fel. rec. Decessor Noster, statim ac Pontificatum suscepit, secum ipse reputans quanto foret usui, ad disciplinam ecclesiasticam restituendam firmandam, si gravibus illis, quae supra enarravimus, incommodis sollicite mederetur, consilium iniit universas Ecclesiae leges, ad haec usque tempora editas, lucido ordine digestas in unum colligendi; amotis inde quae abrogatae iam essent aut obsoletae; aliis, ubi opus esset, ad nostros praesentes mores opportunius accommodatis; aliis etiam, si quando necesse esse aut expedire videretur, ex novo constitutis». Benedicto XV, Const. Ap. Providentissima Mater Ecclesia (27-V-1917), AAS 9.2 (1917) 6. 
de los cánones sobre la potestad episcopal ${ }^{17}$. Y la explicación contractualística del matrimonio tal y como la exponía Gasparri en su tratado, marcó profundamente toda la disciplina codicial sobre el matrimonio ${ }^{18}$. De este modo, la primera codificación canónica no sólo consolidó una de las posibles soluciones legales precedentes, sino que "oficializó" algunas doctrinas al tomarlas como fundamento de su legislación. De nuevo, tomar nota de esta realidad, ayuda a no minimizar los cambios que, de hecho, supuso la promulgación del código pío-benedictino.

Para conocer el modo en que se tomaron estas decisiones y medir su alcance real en cada caso, deben recorrerse tres caminos complementarios: el que permite conocer el derecho vigente antes del código y las elaboraciones doctrinales, que servían para explicarlo y sistematizarlo; el que estudia el proceso de redacción de los cánones a través del estudio de los votos y de las distintas versiones hasta la aprobación del texto definitivo; y, finalmente, el que estudia el resultado final, los cánones del código tal cual fueron promulgados, y de las fuentes que Gasparri señaló como justificación de éstos.

En este apartado me propongo realizar el estudio, a través de esta triple vía, de la cuestión de la idoneidad para acceder a las órdenes sagradas. Como se ha explicado en la Introducción, se persigue una doble finalidad: en primer lugar, la de ilustrar el modo en que se tomaron las "decisiones" que dieron lugar a la legislación codicial, en un tema no estudiado todavía, con la finalidad de verificar tanto elementos de continuidad como de novedad o ruptura; y, en segundo lugar, ilustrarlo a través de una cuestión que, debido a la temática del próximo Sínodo de los Obispos, reviste una cierta actualidad.

En efecto, como sintetizaba el padre Cappello, la vocación, cuando se comprende adecuadamente, consta de un triple elemento: la llamada por parte de Dios, la idoneidad canónica por parte del candidato y la admisión al estado eclesiástico por parte del obispo ${ }^{19}$. Este modo esquemático de presentar

17 Vid, ahora, al respecto, O. CONDORELLI, Recezione della tradizione nella codificazione latina. Il caso del potere dei vescovi, en E. BAURA - N. Álvarez DE las Asturias - T. Sol (cur.), La codificazione e il diritto nella Chiesa, Milano 2017, 121-168.

18 Vid. C. FanTaPPIE, Ecclesiologia e canonistica, Venezia 2015, 399-439, y T. Sol, Codificazione e canonizzazione delle dottrine. Il caso del matrimonio, en La codificazione e il diritto nella Chiesa, 169-202.

19 «Vocatione adaequatae sumptam, constare triplici elemento, scil. speciali vocatione ex parte Dei, canonica idoneitate ex parte candidati, quatenus is omnibus animi et coporis fulgeat qualitatibus ad ministerium sacerdotale rite exercendum requisitis, et admissione ad statum ecclesiasticum ex parte Episcopi». F. M. CAPPELlo, Tractatus Canonico-Moralis. De sacramentis, vol. IV, TauriniRomae 1951, 266. 
la realidad, admite sin duda más de un matiz, pero sirve para señalar el papel esencial que tradicionalmente se ha concedido en la Iglesia a la cuestión de la idoneidad en toda su pastoral vocacional.

En el estudio de la idoneidad requerida, me centraré en aquellos aspectos de índole más subjetiva, excluyendo, por lo general, todo lo referido a la edad, las irregularidades y el título de ordenación, y fijándome también en los medios propuestos para poder verificarlos. También excluyo el estudio de la libertad requerida para la validez o licitud de la ordenación.

\subsection{La idoneidad en el fus canonicum de A. Pillet $y$ en el Ius Decretalium de F. X. Wernz}

La cuestión de la idoneidad para recibir las órdenes sagradas estaba presente también, como no podía ser de otra manera, en las obras de los canonistas inmediatamente anteriores o contemporáneos a la elaboración del código. Para ilustrar la cuestión, quiero referirme a dos obras, diversas tanto en su sistemática como en su planteamiento, aunque, como se verá, prácticamente coincidentes en esta materia.

La primera de las obras, el fus canonicum de A. Pillet, se encuadra entre los intentos privados de ofrecer una exposición "codificada" del derecho canónico, y fue publicado por primera vez en 1890 . Se trata de un texto brevísimo, compuesto por 2.004 artículos y unos apéndices, que comienzan con el Syllabus de Pío IX ${ }^{20}$. Su autor se formó en las aulas del Seminario romano de San Apolinar y enseñó durante largos años en la Universidad Católica de Lille, siendo -según Ruffini- un claro exponente de la visión ultramontana de la Iglesia y de su derecho ${ }^{21}$.

La segunda obra es el conocidísimo Ius Decretalium de F. X. Wernz, jesuita y profesor en la Gregoriana ${ }^{22}$. Se trata de una obra enciclopédica, publi-

${ }^{20}$ Vid. A. Pillet, Fus Canonicum generale distributum in articulos, Parisiis ${ }^{2} 1900$.

${ }^{21}$ Una breve reseña biográfica en C. FANTAPPIE, Chiesa Romana..., cit., II, 1205. «Ma questo Monsignor Pillet è un ben terribile uomo, che vuol rimettere il modo a rumore ed a soqquadro e si serve del codice como di un tizzone da gettare nel campo nemico. Niente affatto. Quel suo vagheggiato codice, tutto irto delle sentenze del Sillabo, è per lui un ramo di ulivo, e lo strumento infallibile della pacificazione definitiva tra la Chiesa e gli Stati». F. RuFfinI, 89.

22 Vid. F. X. WeRnZ, Ius decretalium ad usum praelectionum in scholis textus canonici sive iuris decretalium. Tomus II. Ius constitutionis ecclesiae catholicae, Romae 1909. Una breve reseña biográfica sobre Wernz en C. Fantappiè, Chiesa Romana, II, 1215. Vid. también R. PuZA, P. Franz Xaver Wernz. Kanonist und Fesuitengeneral, Periodica 83 (1994) 351-373. Ruffini, lo consideraba uno 
cada en 1909, que buscaba presentar el derecho canónico vigente siguiendo la sistemática del índice de las colecciones del Corpus Iuris Canonici. Como se sabe, la oposición del padre Wernz a la codificación, se mantuvo a lo largo de todo el proceso de reforma del derecho canónico, en el que participó como consultor ${ }^{23}$. Sin embargo, su obra fue considerada tan cercana a lo que posteriormente sería el código de 1917, que pudo ser fácilmente adaptado por Vidal para que pudiera usarse como manual que sirviera para explicarlo ${ }^{24}$.

Se trata, pues, de dos obras todo lo distintas que se pueden encontrar, tanto por el lugar de formación de los autores, como por su lugar de enseñanza, como, sobre todo, por su diferente aprecio de la técnica codicial.

\subsubsection{La presentación de A. Pillet}

La obra de Pillet está estructurada en tres grandes tratados (de personis, de rebus y de judiciis et de poenis), precedidos por unos prolegomena, donde se inscribe la temática propia de las normas generales. Cada tratado está dividido en libros, títulos, capítulos, secciones y parágrafos.

La cuestión de la idoneidad se incluye en el segundo tratado, libro primero, capítulo octavo, primera sección, dedicada al sacramento del orden desde el punto de vista de quien lo recibe y está dividida en dos parágrafos: referido, el primero, a los requisitos negativos o irregularidades, y, el segundo, a los requisitos positivos.

Por lo que se refiere a los positivos, señala piedad (art. 1079), edad (arts. 1080-1084), ciencia (arts. 1085-1088), libertad (arts. 1089-1092) y título legítimo de ordenación (arts. 1093-1107). Como medios de verificación, las letras testimoniales y el examen realizado por sacerdotes y otros hombres prudentes designados por el obispo (arts. 1077-1078).

Hay que remarcar que el requisito de la piedad se cita como algo previo a los otros requisitos positivos (praeter absentiam irregularitatis et animae

más entre aquellos que «non hanno fatto che rispecchiare nelle loro opere le dottrine del più pretto sapor curialistico, pero non dire addirittura ultramontano, che immaginare si possano. $\mathrm{E}$ che avevano a fare di diverso, si domanderà e non a torto, data la loro qualità di semplici trattatisti del diritto vigente e per di più di trattatisti ufficiali della Chiesa?». F. RUFFINI, La codificazione..., cit., 87.

23 Sobre su crítica a la sistemática del proyecto de código y al abandono del orden clásico de las colecciones de decretales, vid. C. FANTAPPIÈ, Chiesa Romana..., cit., II, 770-778.

${ }^{24}$ Vid. F. X. WERnZ - P. VIDAL, Ius Canonicum ad Codicis normam exactum, 7 vols., Romae 1925. 
pietatis, requiri etiam Ecclesia...), pero sin determinar su alcance exacto ${ }^{25}$. Sobre la ciencia necesaria, en cambio, se afirma que, para el presbiterado, debe comprobarse a través de un examen previo, si son capaces de enseñar al pueblo lo necesario para la salvación y de administrar los sacramentos (art. 1088) ${ }^{26}$.

Por último, la obra de Pillet dedica apenas dos artículos a los seminarios, señalando tan solo la necesidad de que exista uno en cada diócesis y que se regule conforme a los decretos del concilio de Trento (vid. arts. 15071508).

Como se ve, la obra de Pillet, recoge las afirmaciones sustanciales al respecto que hemos encontrado en la tradición canónica, sobre todo en Trento, sin aportar novedad alguna en el contenido y ofreciendo una sistemática muy sencilla, pero con ciertas imperfecciones. La más evidente, quizás, comenzar por los medios de verificación antes que por aquello que hay que verificar.

\subsubsection{La idoneidad en la obra de Wernz}

El segundo tomo del Ius decretalium, está dedicado a la constitución de la Iglesia católica. Está dividido en dos partes y, cada una de ellas, en capítulos, títulos y epígrafes, divididos estos últimos en parágrafos. Todo el volumen lleva, además una numeración continua, siendo la numeración de los títulos también continua. Tanto en el cuerpo del texto como, sobre todo a pie de página, hay abundantísimas referencias a los textos de la tradición canónica que justifican cada una de sus afirmaciones.

La cuestión de la idoneidad viene tratada fundamentalmente en los títulos sexto y séptimo (que forman parte del capítulo segundo de la primera parte), dedicados respectivamente al sujeto y las cualidades de los ordenandos (título sexto) y a las irregularidades y otros impedimentos (título séptimo). Dentro del título sexto, se establece una distinción entre el sujeto capaz de recibir la ordenación, donde se estudia lo necesario para la validez, y el sujeto

$25 \ll$ Praeter absentiam irregularitatis et animae pietatem, requirit etiam Ecclesia in ordines suscepturis, qualitates positivas, quae sunt: aetas determinata, gradu definitus, scientiae, libertas et titulus ordinationis». A. Pillet, Fus Canonicum..., cit., art. 1079.

26 «Ordinandi ad presbyteratum idonei comprobari debent ad populum docendum ea quae scire omnibus necessarium est ad salutem ac ad administranda sacramenta; et hoc constare debet ex diligenti examine praevio». Ibid., art. 1088. 
legítimo para recibirla, donde se estudia la cuestión de la idoneidad. Por último, se dedica un parágrafo propio a la cuestión del título necesario para ordenarse.

Por lo que se refiere a la idoneidad, Wernz comienza por señalar la vocación divina y la recta intención como las dos cualidades fundamentales, explicitando que la rectitud de intención incluye la intención de perseverar y la de recibir las órdenes mayores, no quedándose tan solo en la tonsura o en la recepción de las menores ${ }^{27}$.

A continuación, subraya la necesidad de que se reciba en gracia de Dios y por personas que están alejadas del pecado mortal y que no hayan incurrido ni en irregularidades ni en censuras, para después incidir, sobre todo, en la necesidad de una vida honesta, caracterizada por la constancia de ánimo y la virtud probada ${ }^{28}$.

Entre las virtudes necesarias para la idoneidad, se requiere la de la castidad de modo especial, debido a la obligación del celibato, que considera difícil de vivir por quienes hayan vivido mal esta virtud en los años inmediatos a la ordenación ${ }^{29}$.

Finalmente, señala la necesidad de la debida ciencia y la necesidad de haber recibido la confirmación y de proceder en la recepción de los distintos órdenes, que componían el estado clerical, por orden y sin saltos.

La cuestión de la ciencia necesaria viene explicitada en el título séptimo, al tratarse su defecto como una irregularidad. Allí refiere Wernz cómo la formación de quienes tienen cura de almas o se dedican a la predicación o a la misión debe ser más esmerada que la requerida simplemente para un ejercicio monástico del ministerio sacerdotal ${ }^{30}$. Y cómo el derecho vigente al respecto era el establecido en los cánones de reforma del concilio de Trento, donde se exige a los sacerdotes -como se ha visto que también recordaba Pillet-, la capacidad de instruir a los fieles en lo necesario para la salvación y la de celebrar

27 «Imprimis ordinandus praeditus sit oportet vera vocatione divina et recta intentione». F. X. WERnZ, Ius Decretalium..., cit., 107 y nt. 15.

28 «Praeter immunitatem a peccatis gravibus, censuris, irregularitatibus, impedimentis, necessarium est, ut ordinandus positiva vitae honestate praestet, quae virtute probata et animi constantia commendetur». Ibid., 107.

29 «Coelibatus obligatio, quae ordinibus sacris adnexa est, profecto accurate et constanter non facile servabitur, si vita lasciva sacrae ordinationi immediate praecesserit». Ibid., 107-108.

30 «Quare qui gradus scientiae clericis monsticae vitae addictis forte sufficit, is sacerdotibus saecularibus vel regularibus, qui curae animarum, missionibus habendis, fidei defendendae et propagandae strenuam navant operam, plane insufficiens est dicendum». Ibid., 150-151. 
los sacramentos, debiendo probar dicha capacidad a través de un examen que comprobara diligentemente su idoneidad.

Concluye Wernz su tratamiento de la ciencia necesaria con dos anotaciones de interés. La primera, que siendo los requisitos establecidos por Trento de carácter mínimo, el obispo podría aumentarlos, si bien de modo proporcionado $^{31}$. La segunda, que siendo la ciencia absolutamente necesaria para el ejercicio del ministerio, ni siquiera el Papa podría dispensar de modo absoluto de este requisito ${ }^{32}$. Sí, lógicamente, matizarlo, por ejemplo, no exigiendo en determinados casos grados académicos que el derecho común establece para determinados oficios.

Finalmente, Wernz trata en otro lugar de los medios para verificar la idoneidad de los candidatos, concretamente en el título cuarto, dedicado a los escrutinios y a los requisitos previos a la sagrada ordenación. Allí señala fundamentalmente tres: el seminario, los ejercicios espirituales y los exámenes y escrutinios previos a la recepción de las órdenes.

Sobre la disciplina común vigente respecto al seminario, reconoce que no hay un tiempo determinado, si bien en muchas diócesis sapienter se ha establecido que no se pueda acceder a las órdenes sin haber pasado por lo menos algunos años o meses viviendo en el seminario ${ }^{33}$.

Respecto a la necesidad de los ejercicios previos a las órdenes, a los que se asocia la confesión sacramental, señala que hay legislación pontificia que los obliga en determinadas regiones y que, en otros lugares, obliga bien por leyes particulares, bien por la fuerza de la costumbre ${ }^{34}$.

Por último, sobre los escrutinios y exámenes, Wernz resume una larga historia de legislación, toda ella inspirada en 1 Tm 5,22 (manus cito nemini imposueris), y que se había decantado en el derecho entonces vigente, en tres escrutinios: el que deben hacer los que promueven a los candidatos a las sagradas órdenes antes de presentarlos al obispo, el que debe hacerse el miércoles anterior a las órdenes, delante de un tribunal nombrado por el obispo, y al que

31 «Quod ius Tridentinum cum minimum gradum scientiae statuat, non impedit, quominus Episco$p i$ pro singulis gradibus perfectiorem, sed proportionatam, non exorbitantem requirant scientiam». Ibid., 152.

32 «Cum scientia ad usum ordinum absolute requisita nitatur iure naturali, Rom. Pontifice super bac scientia absolute necessaria dispensatio concedi non potest». Ibid.

33 «Complurium autem dioecesium statutis sapienter cautum est, ne cui saltem ordines sacri conferantur, nisi post definitum tempus aliquot annorum vel mensium in seminario clericali transactum». Ibid., 64.

${ }^{34}$ Cfr. ibid., 65-66. 
corresponde realizar el diligente examen sobre la ciencia requerida y los demás requisitos y, por último, el litúrgico, que se realiza en el seno de la misma ceremonia de ordenación ${ }^{35}$.

Como puede verse, el tratamiento de Wernz es más amplio y se diferencia también en su sistemática del de Pillet de modo notable. Quizás la diferencia más llamativa sea la de la inclusión de la falta de la ciencia necesaria entre las irregularidades y el modo en que divide los medios de verificación de la idoneidad, incluyendo junto a los exámenes tradicionales, dos instituciones propias de la época moderna, si bien de alcance diverso: el seminario y la práctica de los ejercicios espirituales.

\subsection{Los trabajos de redacción y los votos de los consultores}

El proceso de redacción del código pío-benedictino, iniciado con la publicación del Motu Proprio Arduum sane munus (19-III-1904), ha sido calificado por Fantappiè como «la empresa jurídica colectiva más imponente que se ha intentado en Occidente» ${ }^{36}$. En efecto, entre 1904 y 1917, colaboraron en su redacción 18 cardenales, 79 consultores romanos y 40 colaboradores externos, a los que hay que sumar la consulta al episcopado universal y a las universidades pontificias, así como el presidente de la comisión de consultores con sus dos secretarios y el asistente.

En el proceso de los trabajos, exhaustivamente descrito por Fantappiè, tomaron tanto las comisiones de consultores como el consilium directivo, formado de cardenales. La primera tarea fue definir la sistemática general del código y su estructura interna. A continuación, asignar los vota para la redacción de las distintas partes. El trabajo de discusión de los vota y de los schemata-que fueron varios-, se prolongó hasta la vigilia misma de la promulgación de código en el seno de diversas comisiones y con distintas consultas ${ }^{37}$. Para el or-

${ }^{35}$ Cfr. ibid., 67-70.

36 «Non si erra affermando che il codice pio-benedittino s'impone come l'impresa giuridica collettiva più imponente che sia stata tentata in Occidente non solo per l'ampiezza dei materiali e delle fonti giuridiche ridotte a sistema, ma anche per l'elevato numero di redattori e per l'ampiezza del processo di consultazione». C. FANTAPPIÈ, Chiesa romana ..., cit., II, 739-740.

37 Una descripción de los distintos documentos de trabajo que produjeron los distintos protagonistas de estos trabajos, puede verse en J. Llobell - E. DE LEÓN - J. NAVARRETE, Il libro «de processibus»..., cit., 69-86. Fantappiè, por su parte, recoge el testimonio del P. Goyeneche sobre una ultimísima revisión en los primeros meses de 1917. Vid. C. FANTAPPIÈ, Chiesa Romana..., cit., II, 748. 
den de los trabajos, Pío X quiso que, tras las normas generales, se diera precedencia a los sacramentos ${ }^{38}$.

Reconstruir el proceso de elaboración de los cánones referidos a la idoneidad para recibir las órdenes sagradas, exigiría hacer una labor similar a la que han hecho para otros aspectos de la legislación codicial, autores como Llobell, Falchi o Turchi, ya citados. Sería un trabajo más propio de una monografía que de un estudio de estas características. Concretamente, habría que seguir el proceso de redacción a través de los diversos esquemas del código que se conservan en el Archivo Secreto Vaticano, viendo la influencia que tuvieron en los cambios tanto los votos, como los verbales de las comisiones como, finalmente, las anotaciones manuscritas de Gasparri. Me contentaré, aquí, con referir el contenido del único voto que he podido encontrar en ese mismo Archivo -el del capuchino francés Pío de Langogne ${ }^{39}$ - y con hacer una primera aproximación a las variaciones que se observan en los distintos esquemas.

\subsubsection{El voto de Langogne}

El voto ${ }^{40}$ de Langogne se encuentra en la caja 33 y está editado por la tipografía vaticana con fecha de 1906. Cuenta con 35 cánones, profusamente comentados para justificar su redacción y contenido, que ocupan 68 páginas ${ }^{41}$.

Comienza con unas notas introductorias en las que se confronta con las distintas maneras que se encuentran en los tratados para sistematizar esta cuestión, eligiendo finalmente la suya propia, con la que estructurará su voto. Distingue, en efecto, entre sujeto capaz (cc. 1-2), donde trata lo referido a la validez de la ordenación; sujeto legítimo (cc. 3-14), para lo referido a la licitud; sujeto irregular (cc. 15-30) y, finalmente, sujeto impedido (cc. 31-35).

Por lo que se refiere al objeto de nuestra investigación, nos interesan los cánones 3,5 y 6 .

${ }^{38}$ Vid. ibid., 790.

39 Langogne (Francia) 1850-Roma 1914. Una breve noticia biográfica y bibliografía relacionada con él en ibid., 1204.

40 «I "vota" costituiscono normalmente, perlomeno dal punto di vista cronologico, la prima fonte del processo codificatore. In effetti, si tratta dei primi lavori svolti da due o più consultori e collaboratori cui fosse stato affidato un tale compito al finde di avvalersi del loro apporto quale base di partenza del lavoro per la redazione dei futuri schemata». J. LLOBELL - E. DE LEÓN J. NAVARRETE, Il libro «de processibus»..., cit., 70-71.

${ }^{41}$ ASV, fondo codificación, caja 33, voto revmi. P. Pii a Langonio. 
El canon 3, dividido en dos parágrafos, recoge la necesidad de vocación divina, debidamente conocida $(\$ 1)$ y recibirlo en estado de gracia, fortalecido por la confirmación y acompañado por una vida honesta $(\$ 2)^{42}$.

En la justificación de la propuesta, se refiere a las afirmaciones de Wernz sobre la necesidad de la vocación y de la recta intención, señalando que la necesidad de la segunda no debe explicitarse en el canon, pues es el signo principal para reconocer debidamente la vocación, al consistir en una cierta inclinación hacia las cosas de Dios. Concluye, además, que la certeza de la vocación deben tenerla más quienes ordenan que quienes desean ser ordenados, puesto que a ellos compete que el estado clerical no sea invadido por personas indignas ${ }^{43}$.

El canon 5 exige una "ciencia proporcionada" al grado del orden que se va a recibir, señalando en su justificación, la dificultad para explicitar más en qué consiste dicha proporción ${ }^{44}$. Recuerda, en efecto, que tan solo se habían dado hasta el momento algunas indicaciones sobre los planes de estudios, pero sin referir explícitamente los necesarios para cada grado, ni determinar completamente los contenidos. Justifica, además, la inclusión de este canon en este lugar preciso y no entre las irregularidades, al no considerarla estrictamente tal, en contra de la opinión de no pocos canonistas (en el epígrafe anterior hemos visto el caso de Wernz) $)^{45}$.

Por último, el canon 6, precedido de un interrogante, exige haber realizado ejercicios espirituales previos a la ordenación. El interrogante se justifica por considerar que su lugar debería ser otro, no el que a él le corresponde tratar y, su inclusión, por la progresiva importancia que se ha dado a este medio en la legislación precedente, considerando que había llegado el momento de universalizarla.

Tres serían, pues los grandes requisitos más subjetivos para una ordenación lícita -la vocación divina debidamente comprobada, la vida honesta y la ciencia proporcionada-, uno el medio principal para determinarlo -los ejerci-

\footnotetext{
$42 \ll \$ 1$. Nullus promoveatur nisi prius ad statum clericalem divinitus vocatus rite dignoscatur. $\$ 2$. Ordinandus in statu gratiae sit oportet, confirmationisque sacramento iam roboratus et honestate vitae commendabilis». c. 3, Voto Langonio, 9-10.

43 «Item divina vocatio, non tantum ab ipso ordinando sed etiam et maxime ab Ordinante, aut ab eis qui por eo, sedulo perpendatur oporte, ne paulatim coetum clericalem invadant oves et boves et hirci. Hinc in Canone proposito, verba: "rite dignoscatur"». Ibid., 10.

44 «Promovendus scientia praeditus sit oportet Ordini suscipiendo proportionata». c. 5, ibid., 14.

${ }^{45}$ Cfr. ibid., 15.
} 
cios espirituales- y uno el responsable último de verificar que se dan -el obispo o superior legítimo-. Si se compara con los tratados del momento, puede verse tanto la novedad sitemática como la elección u omisión de aspectos referidos a este tema.

\subsubsection{Apuntes sobre la evolución del capitulo de subiecto sacrae ordinationis en el proceso de elaboración del Código}

En la caja 54 del fondo sobre la codificación del Archivo Secreto Vaticano encontramos los verbales de las sesiones de febrero de 1906 sobre el primer esquema de redacción del capítulo, objeto de nuestro estudio. En la caja 86, dos proyectos del Libro III del Código con notas manuscritas de Gasparri: de 1912 y 1913, respectivamente. En la caja 87, el proyecto completo de 1916. Excluyo completamente de este trabajo la presentación de los estudios preparatorios del Libro III (cajas 8 y 9), así como el de las animadversiones al libro III (caja 60) y las animadversiones episcoporum al Código (cajas 83-85).

El primer esquema, el analizado en las reuniones de marzo de 1906, difiere sustancialmente del voto de Langogne. El artículo 1 del capítulo 3, dedicado al sujeto de la ordenación, consta de 16 cánones, referidos a los requisitos para la ordenación lícita, interesando a nuestro estudio el canon 53, que refiere la necesidad de la vocación divina debidamente reconocida, con un tenor idéntico al del voto; y el canon 56, en el que se trata la cuestión de la ciencia requerida, unida ahora a la necesidad de una vida honesta y conforme al orden recibido $^{46}$. La referencia a la necesidad de los ejercicios espirituales desaparece.

En las reuniones de revisión participaron, bajo la presidencia de Gasparri y actuando Pacelli de secretario, Giustini, Melata, Wernz, Bucceroni, Langogne, Bastini Fernández y Esser. El proyecto de los cánones 53 y 56 se discutió el día 25 de febrero de 1906, sin que se tomara nota de nada referido al canon 53.

Sobre el canon 56, algunos manifiestan la necesidad de encontrar modos de decir que no hagan que la "ciencia proporcionada" se interprete de modo abusivo hacia la baja ${ }^{47}$. Por otro lado, mientras Langogne considera que la cuestión de las costumbres están implícitamente incluidas en el canon 53,

${ }^{46}$ Cfr. ASV, fondo codificación, caja 54. El canon 56 dice así: «Promovendus preditus sit oportet scientia ordini suscipiendo proportionata, recta intentione ac moribus non solum bonis et honestis, sed etiam dignis relative ad ordinem de quo agitur, recipiendum». Schema 1906, 2.

47 Cfr. «Consultazione parziale del 25 febbraio 1906», en ibid. 
Wernz pide que el canon se divida en tres parágrafos: uno para la ciencia, otro para las costumbres y otro para la recta intención ${ }^{48}$.

No resulta fácil saber el peso que estas observaciones tuvieron en la redacción del código, pues los esquemas completos que conservamos con anotaciones de Gasparri, difieren notablemente de cuanto se ha señalado hasta aquí. Señalo a continuación, de modo muy esquemático, las variaciones en las cuestiones implicadas en el tema de la idoneidad.

- Proyecto de $1912^{49}$ : el capítulo 2, dedicado al sujeto de la ordenación, inicia con cuatro cánones preliminares (cc. 253-256), para posteriormente tratar, en el artículo primero, de los requisitos de la ordenación. Entre las opciones tomadas conviene destacar: (i) la distinción entre ordenación válida y ordenación lícita en un solo canon, refiriendo para las condiciones de licitud la observancia de los cánones y la ausencia de irregularidades e impedimentos (c. 253); (ii) dedicar un canon a la prohibición absoluta tanto de ordenar a quien no acceda libremente como la de no ordenar a quien, deseándolo, sea idóneo (c. 256); (iii) determinar como situación general el estudio de la ciencia sagrada viviendo en el seminario y señalar la estructura general del currículum de estudios (cc. 257 y 261); (iv) la inclusión de la ciencia requerida y de las costumbres congruentes con el orden recibido junto a otros requisitos en un único parágrafo (c. $259 \$ 1$ ).

- Proyecto de $1913^{50}$ : sobre el texto impreso se encuentran numerosas correcciones y se aporta lo que debería ser su numeración en el conjunto del Código. Mantiene la estructura del proyecto anterior, pero con una serie de diferencias, siendo la principal la desaparición de la vocación divina como constitutivo de un «derecho» a la ordenación, sustituyéndolo por la noción de idoneidad canónica $(\text { c. } 249=972)^{51}$.

48 «Wernz farebbe due distinti paragrafi per la scienza, e per la retta intenzione ed i costumi. Quanto alla scienza direbbe che il "promovendo praeditus sit oportet scientia" CONGRUA ET AB ORDINARIIS DETERMINANDA». Ibid.

49 Cfr. ASV, fondo codificación, caja 86, proyecto 1912.

${ }^{50}$ Cfr. ibid., proyecto 1913.

51 El texto previo decía así: «Nefas est quemquam quovis modo ob quamlibet rationem ad statum clericalem cogere vel vocatum et idoneum ab eodem avertere». Tras las tachaduras y adiciones, la nueva lectura es la siguiente: «Nefas est quemquam quovis modo ob quamlibet rationem ad statum clericalem cogere vel canonice idoneum ab eodem avertere». c. $249=972$ proyecto 1913 , 103. La supresión de la referencia, probablemente está en relación con la controversia sobre el origen de la vocación sacerdotal, que tan vivos debates suscitó a inicios del siglo XX y que, en ocasiones, se mezclaron con la gran cuestión del Modernismo. Vid. al respecto, E. DE LA LAMA, La vocación sacerdotal. Cien años de clarificación, Madrid 1994, 23-60. 
- Proyecto de $1916^{52}$ : la principal novedad es la inclusión de un nuevo canon sobre la necesidad de la certeza de idoneidad que, so pena pecado mortal, debe tener el obispo antes de proceder a la ordenación (c. 975) ${ }^{53}$.

\subsection{Los cánones del CIC'17 y sus fuentes}

Finalmente, el código de 1917, trató la cuestión de la idoneidad en el capítulo 2 del título sexto (el dedicado al sacramento del orden) del libro tercero. Es el capítulo dedicado al sujeto de la sagrada ordenación que, tras unos cánones preliminares (cc. 968-972), se divide en dos artículos: el dedicado a los requisitos (cc. 973-982) y el que recoge las irregularidades (cc. 983-991). Respecto a los esquemas anteriores, el nuevo canon del proyecto de 1916 sobre la necesaria certeza de idoneidad por parte del obispo antes de ordenar, acaba finalmente como parágrafo tercero del canon 973.

En el capítulo tercero del mismo título, se trata de la responsabilidad de los que promueven las vocaciones y, concretamente, de los mecanismos de verificación que deben ponerse. Entre ellos se señalan los exámenes de idoneidad (cc. 996-997) y la necesidad de haber realizado ejercicios espirituales (c. 1001). A la necesidad de formarse en un seminario (ordinariamente como interno), se había dedicado el c. 972.

Finalmente, de los seminarios se trata en el título vigésimo primero del mismo libro tercero, señalándose en los cánones 1364-1366 el currículum de estudios y, en el c. 1371, los principales criterios para expulsar en razón de falta de idoneidad.

Como se dijo, el tercer camino señalado para percibir el alcance de las decisiones tomadas y sus consecuencias en términos de continuidad y de novedad, pasa por el estudio de las fuentes de cada canon, pues, como se sabe, el cardenal Gasparri, se preocupó de que el código fuera pronto publicado junto con sus fuentes. También de que éstas fueran fácilmente accesibles a través de su publicación en una serie de volúmenes que él mismo editó junto con el cardenal húngaro Serédi ${ }^{54}$.

${ }_{52}$ Cfr. ASV, fondo codificación, caja 87, proyecto 1916.

53 «Episcopus qui sacros ordines alicui confert quin ex possitivis argumentis moraliter certus sit de eius canonica idoneitate, non solum gravissime peccat, sed et periculo sese committit alienis communicandi peccatis». c. 975 proyecto 1916, 409.

${ }^{54}$ Cfr. P. Gasparri - I. Serédi (eds.), Codicis Iuris Canonici Fontes, 9 vols., Roma 1926-1939. 
Igualmente se sabe, que sobre las fuentes señaladas pesa la sospecha de que fueron señaladas a posteriori, no siendo necesariamente las tenidas en cuenta a la hora de elaborar los cánones. Servirían en este caso, para ilustrar hasta qué punto la inmensa mayoría de éstos estaban en sintonía con la disciplina precedente, de la que querían ser reflejo fiel.

Por último también, que el código pío-benedictino sólo contempla directamente las fuentes del segundo milenio, accediendo a las del primero únicamente a través del Decreto de Graciano (ca. 1140), que es el texto más antiguo citado.

Teniendo en cuenta estas informaciones, las fuentes reportadas por Gasparri, ofrecen, en cualquier caso, una vía de acceso al menos a parte de la tradición canónica sobre cada cuestión, permitiendo de este modo ver su relación -de mayor o menor continuidad- con la disciplina entonces promulgada.

Con todo, estudiar las fuentes de todos los cánones señalados, resultaría excesivamente prolijo. Me concentraré, por tanto, en los cánones $968 \$ 1,973$ $\$ 3$ y $974 \$ 1$, pues los considero en cierto modo paradigmáticos del planteamiento que tiene el código pío-benedictino sobre esta cuestión. En efecto, en el 968 se determinan, entre los requisitos esenciales del sujeto de la ordenación, el de tener las debidas cualidades a juicio del propio ordinario y la ausencia de impedimentos; en el 973 se prohíbe al obispo ordenar a nadie sin tener la certeza moral acerca de su idoneidad canónica; y, en el 974, se señalan los requisitos principales a tener en cuenta.

\subsubsection{Las fuentes del c. $968 \$ 1$}

El parágrafo primero del canon $968^{55}$, recoge la distinción entre los requisitos de validez y los de licitud, señalando entre los segundos, estar investido de "las debidas cualidades" a juicio del propio Ordinario. Dichas cualidades se explicitarán principalmente en el primer parágrafo del canon 974, que se estudiará posteriormente.

Cuatro son las fuentes señaladas por Gasparri: el Decreto de Graciano, el Liber Extra, un decreto del Santo Oficio y el Pontifical Romano.

$55 \ll$ Sacram ordinationem valide recipit solus vir baptizatus; licite autem, qui ad normam sacrorum canonum debitis qualitatibus, iudicio proprii Ordinarii, praeditus sit, neque ulla detineatur irregularitate aliove impedimento». c. $968 \$ 1$ CIC'17. 
De estas fuentes, buena parte ilustra sólo la necesidad del bautismo para recibir la ordenación; es el caso de uno de los textos de Graciano y de los dos del Liber Extra. El texto del Santo Oficio tampoco aporta nada a nuestro asunto.

Sin embargo, uno de los dos textos citados del Decreto de Graciano, resulta de interés. En realidad, Graciano reporta el canon 19 del concilio de Nicea, que pone en la debida aptitud o capacidad, el límite para que sean reordenados como presbíteros de la Iglesia aquellos que habían pertenecido a sectas heréticas ${ }^{56}$. La presencia de este canon niceno en las colecciones canónicas del primer milenio es cuasi universal, pudiendo de este modo sostenerse que el discurso sobre una cierta aptitud para recibir las órdenes estuvo presente como norma en la práctica totalidad de la historia del derecho canónico ${ }^{57}$.

Por su parte, el título De Ordinibus conferendis del Pontificale Romanum presenta un resumen de toda la disciplina canónica aprobada o reforzada en el concilio de Trento sobre los requisitos para la ordenación ${ }^{58}$. Aparecen, por tanto, la necesidad del examen previo, de la piedad de los candidatos, etc. Esta fuente permite percibir la continuidad legislativa en esta materia, al menos desde el concilio de Trento, siendo el código pío-benedictino, en parte, tan solo una nueva reproposición.

\subsubsection{Las fuentes del c. $973 \$ 3$}

El parágrafo tercero del canon 973 obliga al obispo, bajo pena de gravísimo pecado, a ordenar tan solo aquellos candidatos de los que esté moralmente cierto de su idoneidad canónica ${ }^{59}$. Aparece así ésta como requisito esencial para acceder al sacerdocio y el obispo como responsable último de la verificación.

${ }^{56} \ll$ Si quis confugerit ad ecclesiam catholicam de Paulianistis et Cathafrigis statutum sit, rebaptizari eos omnino debere. Si qui uero clerici erant apud eos, siquidem inculpati fuerint et irreprehensibiles, rebaptizandi sunt, rursus etiam ordinentur ab episcopo ecclesiae catholicae. Si uero examinati minus apti fuerint deprehensi, deponi eos oportet. Similiter autem et circa diacones et de omnibus, qui in eodem clero inueniuntur, eadem forma seruabitur», C. 1, q. 1, c. 52.

57 Una búsqueda completa puede hacerse a través de la base de datos de L. Fowler MAGERL, Clavis Canonum. Selected Canon Law Collections Before 1140. Access with data processing, Hannover 2005.

58 Vid. Pontificale Romanum: Editio princeps (1595-1596), Città del Vaticano 1997, 6-10.

59 «Episcopus sacros ordines nemini conferat quin ex positivis argumentis moraliter certus sit de eius canonica idoneitate; secus non solum gravissime peccat, sed etiam periculo sese committit alienis communicandi peccatis». c. $973 \$ 3$ CIC’17. 
En este caso, las fuentes son más numerosas: tres textos del Decreto de Graciano, uno del Liber Extra y ocho documentos pontificios, siendo el primero de Benedicto XIV y el último del mismo Pío X.

De los textos aducidos del Graciano, el segundo no tiene relación con nuestro tema. Sin embargo, el primero, que es en realidad un canon de los $c a$ pitula Martini, afirma explícitamente que compete al obispo la elección de los presbíteros, teniendo en cuenta su idoneidad ${ }^{60}$. El tercero, que es un fragmento de la epístola de León Magno a los obispos africanos, señala que los obispos que ordenan indignamente, pierden el derecho de ordenar en el futuro $^{61}$. De nuevo, se tratan de textos presentes en las principales colecciones anteriores.

El Liber Extra, por su parte, reporta la constitución 27 del IV concilio de Letrán (1215), donde se establece el modo concreto de proceder para la admisión a las órdenes sagradas, retomando y concretando la praxis precedente ${ }^{62}$.

Por último, los documentos pontificios aducidos tienen en común tomar como punto de partida el texto de $1 \mathrm{Tm} 5,22$, incidiendo habitualmente en que la escasez de sacerdotes no puede disminuir el control de la idoneidad canónica requerida. Esta afirmación puede decirse que constituye un lugar común de toda la reflexión magisterial sobre la pastoral vocacional y lleva a reconducir la responsabilidad del obispo en la cuestión hasta la misma predicación apostólica ${ }^{63}$.

${ }^{60} \ll$ Non liceat populo facere electionem eorum, qui ad sacerdotium promouentur, sed in iudicio episcoporum sit, ut ipsi eum probent, si in sermone et fide et spirituali uita edoctus sit», D. 63, c. 8 .

${ }^{61} \ll$ Si qui episcopi talem consecrauerint sacerdotem, qualem esse non liceat, etiamsi aliquo modo dampnum proprii honoris euaserint, ordinationis ius ulterius non habebunt nec umquam ei sacramento intererunt, quod, neglecto diuino iudicio, inmerito prestiterunt», C. 25, q. 2, c. 24. El summario del texto es taxativo: Ius ordinandi amittunt qui inmeritum consecrant.

${ }^{62}$ Sobre la importancia de esta constitución conciliar y su primera recepción entre los decretalistas, vid. N. ÁlVAREZ DE LAS ASTURIAS, Una Iglesia dibujada canónicamente: las constituciones conciliares, en IDEM (ed.), El IV concilio de Letrán en perspectiva histórico-teológica, Madrid 2016, 71-112, aquí $92-97$.

63 «Melius enim profecto est pauciores habere ministros, sed probos, sed idoneos, atque utiles, quam plures, qui in aedificationem Corporis Christi, quod est Ecclesia, nequicquam sint valituri. Quantam idcirco Episcoporum cautionem ea in re Sacri Canones requirant, non ignoratis Fratres; sed ab eorum norma, quae omnino servari debet, ne patiamini vos abduci humano ullu respectu, vel importunis ambientium suggestionibus, vel fautorum precibus. Apostoli vero praeceptum, ut ne manus cuiquam nimis propere imponantur, tunc potissimum servari necesse est, ubi de promovendis ad Sacros Ordines, et ad Sacratissima Mysteria, quibus nihil est divinius, agendum sit». BENEDICTO XIV, Enc. Ubi primum (3-XII-1740) \$1, en P. GASPARRI - I. SERÉDI, Fontes..., cit., I, 670-674, aquí 671. 


\subsubsection{Las fuentes del c. $974 \$ 1$}

El parágrafo primero del canon 974 señala siete requisitos para recibir lícitamente la ordenación ${ }^{64}$. De ellos, interesan en este estudio el segundo y el tercero, que determinan la necesidad de unas costumbres congruentes con el ministerio a recibir y la ciencia debida, respectivamente. Lógicamente, refiriéndose a tal cantidad de requisitos, las fuentes son numerosas, por lo que me contentaré a poner de manifiesto lo que se encuentra de los periodos anteriores al concilio de Trento.

El primero de los textos referidos por Graciano y aducidos por Gasparri, es un fragmento de Gelasio I en el que se recuerda que tanto la ciencia como la honestidad de vida son requisitos para acceder a las órdenes sagradas ${ }^{65}$. En la misma línea se mueven los papas Hormisdas y León Magno, en otros textos recogidos en el mismo Decreto. El papa León explícitamente señala que la promoción al orden sagrado de alguien indigno resulta más un daño que una ayuda ${ }^{66}$. Finalmente, el texto de Gregorio Magno recogido en la primera cuestión de la Causa 1 incide de nuevo en lo mismo ${ }^{67}$.

Por su parte, el Liber Extra recoge una decretal de Inocencio III en la que explica la costumbre romana referida al escrutinio litúrgico. En ella explica cómo el obispo ordenante no peca si se fía del testimonio dado por el que pre-

${ }^{64} \ll \mathrm{Ut}$ quis licite ordinari possit, requiruntur: $1^{\circ}$ Recepta sacra confirmatio; $2^{\circ}$ Mores ordini congruentes; $3^{\circ}$ Aetas canonica; $4^{\circ}$ Debita scientia; $5^{\circ}$ Ordinum inferiorum susceptio; $6^{\circ}$ Interstitiorum observatio; $7^{\circ}$ Titulus canonicus, si agatur de ordinibus maioribus». c. $974 \$ 1$ CIC'17.

$65 \ll$ Illitteratos aut aliqua parte corporis imminutos, nullus presumat ad clerum promouere, quia litteris carens sacris non potest esse aptus offitiis, et uitiosum nichil Deo prorsus offerri legalia precepta sanxerunt», D. 36, c. 1 .

${ }^{66}$ Cfr. D. 61 , c. 2 y D. 61 , c. 5: $\ll$ Miramur tantum apud uos per occasionem temporis impacati aut ambientium presumptionem aut tumultum ualuisse popularem, ut indignis quibusque et longe extra sacerdotale meritum constitutis pastorale fastigium et gubernatio ecclesiae crederetur. Non est hoc consulere populo, sed nocere, nec prestare regimen sed augere discrimen. Integritas enim presidentium salus est subditorum, et ubi est incolumitas obedientiae, ibi sana est forma doctrinae». Vid. también, en la misma línea, otro fragmento de León Magno en la misma decretal y recogido en D. 78, c. 3: «Quid est: manus cito inponere, nisi ante etatem maturitatis, ante tempus examinis, ante meritum obedientiae, ante experientiam disciplinae sacerdotalem honorem tribuere non probatis? Et quid est: communicare peccatis alienis, nisi talem effici ordinantem, qualis ille est, qui non meruit ordinari?».

${ }^{67} \ll \mathrm{Si}$ quis neque sanctis pollens moribus, uel neque a clero populoque uocatus uel pulsatione coactus, inpudenter Christi sacerdotium, iam quolibet facinore pollutus, iniusto cordis amore, uel sordidis precibus oris, siue comitatu, siue manuali seruitio, siue fraudulento munusculo episcopalem seu sacerdotalem, non lucro animarum, sed inanis gloriae auaritia fultus, dignitatem acceperit, et in uita sua non sponte reliquerit, eumque insperata mors penitentia non inuenerit, procul dubio in eternum peribit», C. 1, q. 1, c. 115. 
senta al candidato; es más, que debe ordenarle, a no ser que tenga conciencia de que sea indigno, caso en el cual no debe proceder a la ordenación. Mientras, el Liber Sextus incluye el canon 15 del II concilio de Lyon (1275), en el que, entre los requisitos para prohibir el acceso a las órdenes sagradas, se encuentra la falta de ciencia ${ }^{68}$.

Finalmente, los decretos de reforma del concilio de Trento, los textos de los pontífices posteriores y los de las congregaciones romanas se mueven en la misma línea, poniéndose de manifiesto la continuidad completa entre la disposición del Código y la tradición canónica.

\section{Consecuencias}

La recepción del primer código de derecho canónico fue "entusiasta" por parte de toda la ciencia canónica; al menos así lo considera Gómez Iglesias después de un atento estudio de literatura canónica inmediatamente posterior a su promulgación ${ }^{69}$. Como si el resultado final hubiera disipado todas las dudas anteriormente puestas de manifiesto desde distintos sectores. A cien años de su promulgación, el entusiasmo ha dado paso a una valoración más crítica.

Desde el punto de vista de la adopción de la técnica codificatoria, se ha pasado de la afirmación oficial -sostenida también por no pocos canonistas-, de que no había introducido ninguna modificación en el contenido del derecho canónico, a una conciencia cada vez más difundida de los cambios que, de hecho, esta técnica trajo consigo ${ }^{70}$. En este sentido, Carlo Fantappiè ha hablado recientemente de un cambio de paradigma, respecto a los modelos precedentes (el medieval y el tridentino), con consecuencias a todos los niveles de la disciplina, enseñanza y ciencia canónica.

En efecto, las disposiciones posteriores de los papas y de las congregaciones romanas acerca de la aplicación del Código y del estudio del derecho

${ }^{68}$ Vid. X.1.12.1 y VI.1.9.4, respectivamente.

69 «Per anni, dopo la sua promulgazione, il "Codex" fu accolto, quasi in maniera unanime, molto positivamente e spesso perfino con entusiasmo». V. GÓMEZ-IGLESIAS C., La ricezione del codice del 1917 nella dottrina e nell'insegnamento, en La codificazione e il diritto nella Chiesa, 72-119, aquí 80.

70 «Il passaggio dalla forma medievale alla forma novecentesca del diritto canonico, nonostante la sotanziale permanenza dei contenuti normativi, ha costituito un vero e proprio cambiamento di paradigma, le cui coneguenze plurime -strutturalmente ambivalenti- restano ancora in gran parte da conoscere e da valutare». C. FANTAPPIE, Dal paradigma canonistico classico al paradigma codificatorio, en ibid., 3-34, aquí 3 . 
canónico, fueron determinantes para el surgimiento de una ciencia canónica diversa, cimentada habitualmente en el método exegético y con una visión del trabajo del canonista radicalmente diversa a la de los periodos posteriores.

Además, la mayor cognoscibilidad del derecho canónico habría llevado a una juridización de buena parte de las disciplinas teológicas, principalmente la teología pastoral, la teología litúrgica y la teología pastoral, contribuyendo de este modo a la consolidación de una praxis eclesial cada vez más rígida y con escaso margen de maniobra para hacer frente a los nuevos problemas planteados por la sociedad del momento ${ }^{71}$.

El alcance de estas afirmaciones debe evaluarse a la luz de los resultados que arrojan los análisis sobre las "decisiones" concretas; las que llevaron a codificar de un modo determinado la disciplina hasta entonces vigentes. En este sentido, por ejemplo, el modo en el que se codificaron las llamadas técnicas flexibilizadoras del derecho, permite aceptar de modo general la afirmación de una mayor rigidez del ordenamiento canónico ${ }^{72}$.

¿Qué decir sobre las consecuencias de las decisiones tomadas en la codificación de todo lo referido a la idoneidad para recibir las órdenes sagradas?

En primer lugar, que la obligatoriedad de aprobar un examen antes de la ordenación (cfr. c. 996) será precisado por sendas instrucciones de la Sagrada Congregación de Sacramentos y de la Sagrada Congregación de Religiosos ${ }^{73}$. En ellas se señalan los elementos necesarios a examinar, para que puedan verificarse todos los requisitos establecidos por el Código ${ }^{74}$. Si a esto se añade la promulgación por Pío XI de la constitución apostólica Deus scientiarum Dominus, para la renovación de los estudios en las facultades eclesiásticas, se puede afirmar que la codificación inició un proceso de concreción de los contenidos

${ }^{71}$ Cfr. C. FANTAPPIÈ, Chiesa Romana ..., cit., II, 1109-1112.

72 Cfr. ibid., 1139-1142. Sobre la codificación de las técnicas de flexibilización del derecho canónico, vid., también, G. Olivero, Dissimulatio e tolerantia nell'ordinamento canonico, Milano 1953; S. BERLINGÒ, La causa pastorale della dispensa, Milano 1973, y E. BAURA, La dispensa canonica della legge, Milano 1997, 89-107.

73 Cfr. S. C. DE SACRAMENTIS, Instr. De scrutinio alumnorum peragendo antequam ad ordines promoveantur (27-XII-1930), AAS 23 (1930) 120; S. C. DE RELIGIOSIS, Instr. De formatione clericali el religiosa alumnorum ad sacerdotium vocatorum deque scrutinio ante ordinum susceptionem peragendo in religionibus clericalibus (1-XII-1931), AAS 24 (1931) 74.

${ }^{74}$ Un comentario a estas instrucciones y, en general a la disciplina codicial sobre esta cuestión en J. SAN José PRISCO, La dimensión bumana de la formación sacerdotal. Aproximación histórica, aspectos canónicos y estrategias formativas, Salamanca 2002, 53-59. 
esenciales de dicha idoneidad, en lo que hoy se consideran los cuatro grandes aspectos de la formación para el sacerdocio: la humana, la espiritual, la intelectual y la pastoral.

En segundo lugar, que la legislación codicial sobre la materia encuentra su ambiente próximo en la renovación sacerdotal iniciada por san Pío X y continuada por su sucesores ${ }^{75}$. En este movimiento de renovación, la cuestión de la idoneidad, con su consiguiente labor de selección, representará un papel fundamental. En este contexto, resulta ilustrativa la cita del c. $973 \$ 3$ en la sección dedicada a la promoción de las vocaciones en la encíclica $A d$ catholici sacerdotii de Pío XI ${ }^{76}$. También, la progresiva mención en los documentos posteriores de la necesidad de vocación divina, desaparecida finalmente del Código, probablemente -como ya se dijo- en relación con el ambiente modernista en el que se desarrolló a inicios del siglo XX la discusión sobre la naturaleza de la vocación sacerdotal ${ }^{77}$.

Por último, que la cuestión de la idoneidad para la recepción del sacramento del orden adquirirá un tratamiento mucho más completo tras la primera codificación canónica en un género científico que tendrá gran peso a partir de entonces: los tratados que armonizan las enseñanzas de la teología moral con la disciplina canónica. El caso del Tractatus Canonico-Moralis del padre Felix Cappello resulta ilustrativo en este caso $^{78}$.

\section{CONCLUSIÓN}

Comenzaba este estudio señalando que el centenario de la primera codificación canónica había encontrado a la investigación histórica bien preparada. Estamos, en efecto, en condiciones de analizar históricamente el código

75 Cfr. Pío X, Exh. Ap. Haerent animo (4-VIII-1908).

${ }^{76}$ «Pero la responsabilidad principal será siempre la del obispo, el cual, según la gravísima ley de la Iglesia, no debe conferir las sagradas órdenes a ninguno de cuya aptitud canónica no tenga certeza moral fundada en razones positivas; de lo contrario, no sólo peca gravísimamente, sino que se expone al peligro de tener parte en los pecados ajenos». Pío XI, Enc. Ad catbolici sacerdotii (20XII-1935) 56.

77 Sobre la progresiva mención de la vocación y su explicación también como acontecimiento interior, vid. cuanto expone E. DE LA LAMA, La vocación sacerdotal..., cit., 60-72.

78 El tratamiento de la cuestión de la vocación al orden sagrado, ocupa los números 363-377, incluyendo en la reflexión todo lo referido a la polémica sobre el origen de la vocación sacerdotal e incorporando los desarrollos disciplinares y magisteriales posteriores al código pío-benedictino. Vid. F. M. CAPpello, Tractatus..., cit., IV, 265-278. 
pío-benedictino y de sacar, también desde el conocimiento histórico, no pocas conclusiones.

No hay que olvidar, sin embargo, que son conclusiones que deben tener en cuenta otras cuestiones deliberadamente dejadas de lado en este trabajo. Concretamente, el profundo antijuridicismo que ha marcado la vida de la Iglesia desde los albores de los años sesenta, ¿no habrá sido en parte consecuencia de un exceso de juridización? La consolidación en el Código de un modelo de Iglesia ya centenario, ¿no retrasó excesivamente e hizo traumática la reforma propiciada por el concilio Vaticano II? Las debilidades aplicativas de nuestro actual código, ¿no están motivadas ab origine por un deseo de distanciarse de la experiencia previa, cuyas consecuencias negativas todavía pesaban mucho en el momento de su elaboración? Son cuestiones que necesariamente hay que afrontar, si se quiere que la historia siga siendo magistra vitae, pero una conmemoración como la presente no es probablemente el lugar.

En el caso que nos ha ocupado, el de la cuestión de la idoneidad, considero, sin embargo, que el primer código canónico ha contribuido notablemente a una cuestión permanentemente considerada esencial por parte de la Iglesia.

Contribución notable porque sirvió para hacer cognoscibles los requisitos para la licitud de la ordenación, como para comenzar a precisar los contenidos concretos de algunos de ellos. También porque estableció mejor los medios de verificación y resaltó, sin quitar nada de su fuerza a la formulación tradicional, la responsabilidad del obispo en el discernimiento último del cumplimiento o no de estos requisitos ${ }^{79}$.

Desde este punto de vista particular, el código de 1917 es, a la vez, reflejo de la tradición canónica y del contexto de renovación sacerdotal iniciado por Pío X y continuado por sus sucesores. Tradición y contexto de renovación en el que los criterios objetivos desempeñaban un papel fundamental en el discernimiento vocacional.

Quizás, en este sentido, ofrecen una preciosa enseñanza a la Iglesia actual, invitada por el papa Francisco a reflexionar de nuevo sobre el discerni-

79 «Sólo deben ser ordenados aquellos que, según el juicio prudente del Obispo propio o del Superior mayor competente, sopesadas todas las circunstancias, tienen una fe íntegra, están movidos por recta intención, poseen la ciencia debida, gozan de buena fama y costumbres intachables, virtudes probadas y otras cualidades físicas y psíquicas congruentes con el orden que van a recibir». c. 1029 CIC'83. 
miento vocacional y embarcada en la tarea de aplicar una nueva ratio para la formación de los candidatos al sacerdocio ${ }^{80}$. La enseñanza del valor de los criterios objetivos -aquellos que se han visto aquí y que, de otro modo formulados, siguen presentes en el código vigente- para acertar en el discernimiento, y el de la responsabilidad del obispo -también en un momento en el que la crisis hace de la promoción de vocaciones una cuestión angustiosa- de verificarlos cuidadosamente en cada caso.

${ }^{80}$ Cfr. CONGREgación PARA El Clero, El Don de la vocación presbiteral. Ratio fundamentalis institutionis sacerdotalis (8-XII-2016). 


\section{Bibliografía}

Álvarez de las Asturias, N., Il Codice di Diritto Canonico di 1917 quale oggetto storico, Ius Ecclesiae 23 (2011) 745-763.

—, Derecho canónico y codificación: Alcance y límites de la asunción de una técnica, Ius Canonicum 51 (2011) 105-136.

—, Una Iglesia dibujada canónicamente: las constituciones conciliares, en IDEM (ed.), El IV concilio de Letrán en perspectiva bistórico-teológica, Madrid 2016, 71-112.

AstorRI, R., Le leggi della Chiesa tra codificazione latina e diritti particolari, Padova 1992.

BAURA, E., La dispensa canonica della legge, Milano 1997.

Benedicto XIV, Enc. Ubi primum (3-XII-1740).

Benedicto XV, Const. Ap. Providentissima Mater Ecclesia (27-V-1917), AAS 9.2 (1917).

Berlingò, S., La causa pastorale della dispensa, Milano 1973.

Cappello, F. M., Tractatus Canonico-Moralis. De sacramentis, vol. IV, TauriniRomae 1951.

Cattaneo, A. (cur.), L'eredità giuridica di San Pio X, Venezia 2006.

Condorelli, O., Recezione della tradizione nella codificazione latina. Il caso del potere dei vescovi, en E. BAURA - N. Álvarez DE las Asturias - T. Sol (cur.), La codificazione e il diritto nella Chiesa, Milano 2017, 121-168.

CONGRegación para El Clero, El Don de la vocación presbiteral. Ratio fundamentalis institutionis sacerdotalis (8-XII-2016).

DE la Lama, E., La vocación sacerdotal. Cien años de clarificación, Madrid 1994.

—, Historia, en C. IzQuierdo (dir.), Diccionario de Teología, Pamplona 2006, 439-459.

DiENI, E., Tradizione juscorporalista e codificazione del matrimonio canonico, Milano 1999.

DiLThey, W., El mundo bistórico, México 1944.

FALCHI, F., I chierici nel processo di formazione del codice pio-benedettino, Padova 1987.

FANTAPPIÈ, C., Chiesa Romana e modernità giuridica, Milano 2008.

—, Ecclesiologia e canonistica, Venezia 2015.

-, Dal paradigma canonistico classico al paradigma codificatorio, en E. BAURA N. Álvarez De las ASTURIAS - T. Sol (cur.), La codificazione e il diritto nella Chiesa, Milano 2017, 3-34. 
—, El código de derecho canónico de 1917 y sus repercusiones para la vida de la Iglesia, Ius Communionis 5 (2017) 209-224.

FeliCiani, G., Il Concilio Vaticano I e la codificazione del diritto canonico, en Studi in onore di Ugo Gualazzini, vol. 2, Milano 1981, 35-80.

—, Lineamenti di ricerca sulle origini della codificazione canonica, en IDEM, Le pietre, il ponte e l'arco. Scritti scelti, Milano 2012, 3-17.

Fowler Magerl, L., Clavis Canonum. Selected Canon Law Collections Before 1140. Access with data processing, Hannover 2005.

Gasparri, P. - Serédi, I. (eds.), Codicis Iuris Canonici Fontes, 9 vols., Roma 1926-1939.

GHERRI, P., Codificazione canonica tra tecnica e sistema, Eastern Canon Law 2 (2013) I, 19-130.

GómeZ-Iglesias C., V., Acerca de la trascendencia bistórica de la iniciativa de san Pío X de elaborar un código de derecho canónico, Ius Ecclesiae 29 (2017) 51-76.

—, La ricezione del codice del 1917 nella dottrina e nell'insegnamento, en E. BAURA - N. Álvarez DE las ASTURIAS - T. SOL (cur.), La codificazione e il diritto nella Chiesa, Milano 2017, 72-119.

Grossi, P., Chiesa Romana e modernità giuridica (a proposito di un'opera recentissima di Carlo Fantappiè), en IDEM, Scritti canonistici, ed. de C. FANTAPPIÈ, Milano 2013, 293-312.

Llobell, J. - De León, E. - Navarrete, J., Il libro «De processibus» nella codificazione del 1917. Studi e documenti, vol. I, Milano 1999.

Minelli, C., Pio X e l'avvio del processo di codificazione, Stato, Chiese e pluralismo confessionale, Rivista telematica (www.statochiese.it) n. 33/2013.

MORI, G., I religiosi nella codificazione canonica pio-benedettina. Sedimentazioni e nuovi assetti, Firenze 2004.

Olivero, G., Dissimulatio e tolerantia nell'ordinamento canonico, Milano 1953.

PADOA Schioppa, A., Storia del diritto in Europa. Dal medioevo all'età contemporanea, Bologna 2007.

Pillet, A., Fus Canonicum generale distributum in articulos, Parisiis ${ }^{2} 1900$.

Pío X, Exh. Ap. Haerent animo (4-VIII-1908).

Pío XI, Enc. Ad catbolici sacerdotii (20-XII-1935).

Pontificale Romanum: Editio princeps (1595-1596), Città del Vaticano 1997.

PuZA, R., P. Franz Xaver Wernz. Kanonist und fesuitengeneral, Periodica 83 (1994) 351-373. 
RUFFINI, F., La codificazione del diritto ecclesiastico, ahora en IDEM, Scritti giuridici minori, Milano 1936, I, 61-97.

SAN José Prisco, J., La dimensión humana de la formación sacerdotal. Aproximación histórica, aspectos canónicos y estrategias formativas, Salamanca 2002.

S. C. DE ReLigiosis, Instr. De formatione clericali el religiosa alumnorum ad sacerdotium vocatorum deque scrutinio ante ordinum susceptionem peragendo in religionibus clericalibus (1-XII-1931), AAS 24 (1931) 74.

S. C. DE SACRAMENTIS, Instr. De scrutinio alumnorum peragendo antequam ad ordines promoveantur (27-XII-1930), AAS 23 (1930) 120.

SEDANO, J., Iglesia y modernidad jurídica. Una contribución a la historia del pensamiento jurídico moderno en la monografía de Carlo Fantappiè, Ius Canonicum 52 (2011) 767-798.

SíNODO DE LOS OBISPOS, Los jóvenes, la fe y el discernimiento vocacional: documento preparatorio para la XV Asamblea Ordinaria.

Sol, T., Codificazione e canonizzazione delle dottrine. Il caso del matrimonio, en E. BAURA - N. Álvarez DE las ASTURIAS - T. Sol (cur.), La codificazione e il diritto nella Chiesa, Milano 2017, 169-202.

STERN, J. (ed.), Thibaut y Savigny. La Codificación: una controversia programática basada en sus obras 'Sobre la Necesidad de un Derecho Civil General para Alemania' y 'De la vocación de nuestra época para la legislación y la ciencia del Derecho' con adiciones y juicios de sus contemporáneos, Madrid 1970.

TURCHI, V., Le disposizioni preliminari sul matrimonio nel processo di codificazione piano-benedettino, Napoli 2001.

VIDAL, P., Ius Canonicum ad Codicis normam exactum, 7 vols., Romae 1925.

Vismara Missiroli, M. - Musselli, L., Il processo di codificazione del diritto penale canonico, Padova 1983.

WERNZ, F. X., Ius decretalium ad usum praelectionum in scholis textus canonici sive iuris decretalium. Tomus II. Ius constitutionis ecclesiae catholicae, Romae 1909. 